\title{
A Longitudinal Study of Child Development in Children Enrolled in Brazilian Public Daycare Centers
}

\author{
Luis Anunciação \\ Dept. of Psychology, Pontifical Catholic University of Rio de Janeiro \\ 22451-900, Rio de Janeiro, Brazil \\ Tel: 55-21-3527-1001Ｅ-mail: luisfca@gmail.com
}

Jane Squires

Early Intervention/Special Ed., University of Oregon

901 E 18th Ave., Suite 351, Eugene, OR, United States

Tel: 1-541-346-2634Ｅ-mail: jsquires@uoregon.edu

\section{J. Landeira-Fernadez}

Dept. of Psychology, Pontifical Catholic University of Rio de Janeiro

22451-900, Rio de Janeiro, Brazil

Tel: 55-21-3527-1001Ｅ-mail: landeira@ puc-rio.br

Received: January 29, 2018

Accepted: March 3, 2017 Published: March 10, 2018

doi:10.5296/gjes.v4i1.12555

URL: https://doi.org/10.5296/gjes.v4i1.12555

\begin{abstract}
A longitudinal research study was conducted that examined aspects of child development in children who were enrolled in public daycare centers in Brazil. The participants were 596 children (1-3 years old, $\mathrm{n}=51 ; 2-4$ years old, $\mathrm{n}=545$ ) who were enrolled in 198 public daycare centers in Rio de Janeiro, Brazil. Communication, gross motor, fine motor, problem-solving, and personal-social domains were assessed using the Brazilian version of the Ages and Stages Questionnaire, 3rd edition, adapted for public child daycare centers. A Bayesian robust regression model was performed to check for gender and age differences and interactions. The findings indicated main effects of gender and age. Females had higher scores than males in the communication and personal-social domains. No interactions were
\end{abstract}




\section{Macrothink}

Global Journal of Educational Studies ISSN 2377-3936

found, suggesting the absence of moderation effects between age and gender. This study provides information about child development, especially in children who are enrolled in public daycare centers in Brazil.

Keywords: Child Development, Psychometrics, Bayesian inference, Ages and Stages Questionnaires 


\section{Introduction}

Child development is a dynamic process and refers to the sequence of physical, language, thought, and emotional changes that occur in a child from birth to the beginning of adulthood. Monitoring developmental processes enables the determination of child and family vulnerabilities and strengths over time, which is important for supporting children in reaching their developmental potential or providing specialized services when needed.

Studies have shown that the monitoring process is even more important in low-income countries because caregivers and healthcare providers may not be sufficiently equipped with knowledge about early childhood development and because low-income environments increase the odds of children having developmental delays or other early adversity (Ertem et al., 2008; Schonhaut, Armijo, Schonstedt, Alvarez, \& Cordero, 2013; van Heerden, Sen, Desmond, Louw, \& Richter, 2017).

In Brazil, the education system is composed of both public and private sectors. The former does not require direct payment and is funded entirely by the state. The latter requires direct payment, which is often provided by parents. Both systems have the same flow: (i) daycare services for infants aged 6 months to 4 years, (ii) preschool services between 4 and 6 years old, (iii) fundamental instruction between 6 and 14 years old, and (iv) high school between 15 and 17 years old. Rio de Janeiro's municipal public education network is also composed of Early Childhood Development Spaces, where nursery and preschool facilities are together in a space that is equipped with materials to provide stimulation for child development (Rio de Janeiro City, 2017).

Despite this overall structure, the public system faces several challenges. The rates of violation of the rights of children are still high, and there is a lack of providing for basic needs. Some children and families who access the network are residents of slums in high-poverty areas, often controlled by drug dealers and other criminal elements. This socioeconomic status places them in a situation of extreme vulnerability. Food insecurity and school dropout rates are high. This scenario impacts the entire system, and the overall quality of these daycare centers is probably not very high relative to similar centers in developed countries (Elwick, 2018; Fonseca, Sena, dos Santos, Dias, \& de Melo Costa, 2013).

During 2009 and 2012, the city of Rio de Janeiro, in cooperation with the Strategic Affairs Secretariat of the Presidency of the Republic (SAE/PR), implemented a program to reform basic education schools. One of the key aspects of this program relied on measuring child development using the Brazilian version of the Ages and Stages Questionnaire, 3rd edition (ASQ-BR; Filgueiras, Pires, Maissonette, \& Landeira-Fernandez, 2013). However, few results are reported in the literature. The aim of the present study was to investigate the development of children who were enrolled in public daycare centers in Brazil and identify possible gender and age differences and interactions in the five domains of child development, assessed by the ASQ-3. 


\section{$\triangle$ Macrothink}

\section{Method}

\subsection{Participants}

The sample was recruited as part of a larger educational program in Rio de Janeiro, Brazil. For this research, based on the children's age, two groups were formed. In the first group $(\mathrm{n}=$ $51,53 \%$ female), the children were 1-year-old at the first measurement time point (2010), and they were 3 years old at the last measurement time point (2012). The second group ( $\mathrm{n}=545$, $44 \%$ female) comprised children who were 2 years old at the first measurement time point. Table 1 reports the sociodemographic characteristics of the participants.

Table 1 reports the sociodemographic characteristics of the participants.

\begin{tabular}{lcccc}
\hline & \multicolumn{2}{c}{$\mathbf{1 - 3}$ years old } & \multicolumn{2}{c}{$\mathbf{2 - 4}$ years old } \\
\hline Sex & No. & Proportion & No. & Proportion \\
Male & 24 & $47 \%$ & 304 & $56 \%$ \\
Female & 27 & $53 \%$ & 241 & $44 \%$ \\
Total & 51 & $100 \%$ & 545 & $100 \%$
\end{tabular}

\begin{tabular}{lcccc}
$\begin{array}{l}\text { No. of children in each Regional Education Coordination } \\
1\end{array}$ & \multicolumn{1}{l}{} & \\
1 & 3 & $6 \%$ & 75 & $14 \%$ \\
2 & 5 & $10 \%$ & 71 & $13 \%$ \\
3 & 9 & $18 \%$ & 57 & $10 \%$ \\
4 & 12 & $24 \%$ & 69 & $13 \%$ \\
5 & 3 & $6 \%$ & 24 & $4 \%$ \\
6 & 3 & $6 \%$ & 38 & $7 \%$ \\
7 & 6 & $12 \%$ & 29 & $5 \%$ \\
8 & 2 & $4 \%$ & 71 & $13 \%$ \\
9 & 0 & $0 \%$ & 49 & $9 \%$ \\
10 & 8 & $16 \%$ & 62 & $11 \%$ \\
Total & 51 & $100 \%$ & 545 & $100 \%$ \\
\hline
\end{tabular}

${ }^{1}$ In 2012, Rio de Janeiro city had 10 Regional Education Coordinations in all city extensions.

\subsection{Measures: $A S Q-B R$}

The ASQ-3 is a caregiver report screening questionnaire for children aged 4 months to 5 years, which is completed with the caregiver by a trained assessor. The application time is 10-15 minutes. This instrument was designed to follow a child's development over time and provide a dependable and cost-effective strategy for the early identification of children who may require further assessment and who may benefit from some type of intervention (Bricker, Macy, Squires, \& Marks, 2013).

The ASQ-3 comprises five subscales, including communication, gross motor, fine motor, problem-solving, and personal-social domains. Each domain consists of six questions, and caregivers must respond with "yes," "sometimes," or "not yet." These responses are then translated to numerical values (10,5, and 0 , respectively).

The initial work on the ASQ-3 began in 1979, and the scales have been successfully adapted to several languages, including Spanish (Armijo, Schonhaut, \& Cordero, 2015), Chinese (Wei et al., 2015), Korean (Heo \& Squires, 2012), and Brazilian Portuguese (Filgueiras, Pires, 
Maissonette, \& Landeira-Fernandez, 2013). The Brazilian version of the ASQ-3 (ASQ-BR) was adapted for public child daycare centers. Psychometric studies concluded that the ASQ-BR is a valid and reliable screening tool for children who are enrolled in public daycare centers (Filgueiras et al., 2013). Because of the longitudinal follow-up in the present study, we used only selected months from the ASQ-BR (i.e., 12, 24, 26, and 48).

\subsection{Procedure}

A 1-day, 8-hour meeting was scheduled by the Education Secretary of the City of Rio de Janeiro, and all of the directors of the 468 public child daycare centers were invited to participate. In each meeting, the ASQ-BR was presented by a person who was previously trained, and the directors were responsible for taking the ASQ-BR back to their daycare centers and instructing their teachers on how to administer it in their classrooms. Children were evaluated by their teachers during the second semester in 2010, 2011, and 2012. Each classroom had an average of 30 children.

\subsection{Statistical Analysis}

\subsubsection{Dataset and Descriptive Statistics}

The dataset had no missing values. Each total score was computed as the sum of all items for each dimension. This method relies on the ASQ manual. Descriptive statistics (mean, standard deviation, median, and median absolute difference) were computed for all ASQ-BR intervals. These results are reported by age and gender. A Bayesian regression model was performed to check for gender and age differences and interactions. To deal with outliers, the model error term was assumed to be Student's $T$-distributed with $v$ using a wide Gamma prior, as proposed in the literature (Bürkner, 2017; Ding, 2014). Males were assigned to the reference groups as well the first age of the group (i.e., for children aged 2-4, 4 was the reference category). All of the analyses were performed using $R$ software (R Development Core Team, 2016) with the brms package (Bürkner, 2017).

\subsubsection{Bayesian Robust Regression}

A simple linear model $\left(y_{i}=\alpha+\beta_{1} X_{i}+\epsilon_{i}\right)$ can be written in terms of a probabilistic model: $\mu_{i}=\alpha+\beta_{1} X_{i}$. This model defines $y_{i} \sim N\left(\mu_{i}, \sigma^{2}\right)$, which can be written as $y_{i} \sim N\left(\alpha+\beta_{1} X_{i}, \sigma^{2}\right)$, where $\mu \in(-\infty,+\infty)$ is a location parameter, and $\sigma^{2}>0$ is a scale parameter. In other words, it is assumed that the dependent variable (Y) follows a normal distribution that is parametrized by a mean $\left(\mu_{i}\right)$ that is a linear function of $\mathrm{X}$, parametrized by $\alpha, \beta$, and the standard deviation $\sigma$ (Gelman, Carlin, Stern, \& Rubin, 2004; Kruschke, 2011).

Three techniques for estimating parameters from observed data are routinely performed: Ordinary Least Squares (OLS), Maximum Likelihood Estimator (MLE), and Bayesian Estimator. OLS aims to find the set of $\beta$ that will minimize the squared errors, regardless of the form of the distribution of errors. If the form of the distribution of errors is known, then the MLE can be used to estimate regression coefficients by maximizing the likelihood of the data/joint probability of the observations. Finally, a Bayesian estimate allows setting a prior distribution on the parameters and using Bayes theorem to obtain a posterior distribution that is proportional to the prior and the likelihood. In this approach, instead of maximizing the likelihood function alone, it is necessary to assume a prior distribution for the parameters and use Bayes theorem (Myung, 2003; Rouder, Morey, Speckman, \& Province, 2012): 


\section{MInstitute ${ }^{\text {Mink }}$}

Global Journal of Educational Studies

ISSN 2377-3936

2018, Vol. 4, No. 1

In Bayesian inference, the likelihood function assumes a prior distribution for the estimated parameters as the following:

$$
f\left(\alpha, \beta, \sigma^{2} \mid Y, X\right) \propto \prod_{i=1}^{n} N\left(y_{i} \mid \alpha+\beta X_{i}, \sigma^{2}\right) * f_{\alpha}(\alpha) f_{\beta}(\beta) f_{\sigma^{2}}\left(\sigma^{2}\right)
$$

In psychological research, the data frequently do not meet the normality criteria because of atypical observations, which sometimes imposes different statistical procedures that seek to avoid type I and II errors. Studies have shown that statistical regression models with $T$-distributed errors produce more stable and precise results because the $T$ distribution provides heavy-tails compared with the normal. To model a $T$ distribution, an additional parameter that represents the degrees of freedom ( $v$ ) is necessary (Ding, 2014; Gelman et al., 2004). It is possible to state that the error term follows a bivariate $T$ distribution, $\epsilon_{i} \sim t_{2}\left(\mathrm{O}_{2}, \Omega, v\right)$, with the density function as the following:

$$
f(t ; \mu, \Omega, v)=(2 \pi)^{-1}|\Omega|^{-\frac{1}{2}}\left\{1+v^{-1}(t-\mu)^{T} \Omega^{-1}(t-\mu)\right\}^{-\frac{v+z}{2}}
$$

Because of the lack of prior knowledge, a weakly informative prior (wide Gamma) was considered for $v$, whereas the Normal was considered for the regression coefficients and intercept. The No-U-Turn Sampler (NUTS) was chosen as the sampler, and a draw of 4,000 posterior samples was computed, from which the High Density Interval was computed.

\subsection{Ethical Approval}

Ethical approval for this study was granted by the Ethical Committee of Pontifical Catholic University of Rio de Janeiro (Rio de Janeiro, Brazil).

\section{Results}

All of the scores for boys and girls were computed separately by age according to the ASQ-BR dimensions. Table 2 presents the descriptive results.

Table 2. Longitudinal results of male and female children aged 1-3 years and 2-4 years by

\begin{tabular}{|c|c|c|c|c|c|c|c|c|c|c|c|c|}
\hline & \multicolumn{3}{|c|}{ Male } & \multicolumn{3}{|c|}{ Female } & \multicolumn{3}{|c|}{ Male } & \multicolumn{3}{|c|}{ Female } \\
\hline & 1 year & 2 year & 3 year & 1 year & 2 year & 3 year & 2 year & 3 year & 4 year & 2 year & 3 year & 4 year \\
\hline \multicolumn{13}{|c|}{ Communication } \\
\hline Mean & 33.33 & 51.04 & 48.54 & 39.63 & 50.74 & 54.44 & 40.81 & 51.15 & 53.52 & 45.15 & 51.62 & 54.23 \\
\hline SD & 15.99 & 13.67 & 10.05 & 15.87 & 15.61 & 5.94 & 17.30 & 9.24 & 10.04 & 17.11 & 8.40 & 9.97 \\
\hline Median & 32.50 & 55.00 & 50.00 & 45.00 & 60.00 & 55.00 & 45.00 & 50.00 & 60.00 & 50.00 & 50.00 & 60.00 \\
\hline MAD & 22.24 & 7.41 & 7.41 & 14.83 & 0.00 & 7.41 & 22.24 & 7.41 & 0.00 & 14.83 & 7.41 & 0.00 \\
\hline \multicolumn{13}{|c|}{ Gross motor } \\
\hline Mean & 43.54 & 56.46 & 58.13 & 46.67 & 56.11 & 58.52 & 51.56 & 57.78 & 57.63 & 51.08 & 56.37 & 57.61 \\
\hline SD & 17.41 & 5.61 & 4.12 & 13.52 & 7.38 & 4.56 & 10.54 & 5.68 & 6.47 & 9.88 & 7.79 & 6.49 \\
\hline Median & 42.50 & 60.00 & 60.00 & 50.00 & 60.00 & 60.00 & 55.00 & 60.00 & 60.00 & 50.00 & 60.00 & 60.00 \\
\hline MAD & 25.95 & 0.00 & 0.00 & 14.83 & 0.00 & 0.00 & 7.41 & 0.00 & 0.00 & 14.83 & 0.00 & 0.00 \\
\hline \multicolumn{13}{|c|}{ Fine motor } \\
\hline Mean & 37.50 & 47.71 & 48.54 & 42.22 & 52.41 & 53.15 & 43.16 & 50.26 & 46.81 & 44.52 & 50.81 & 50.54 \\
\hline SD & 15.25 & 10.63 & 14.71 & 13.82 & 9.44 & 11.61 & 11.68 & 13.32 & 13.91 & 12.24 & 12.76 & 12.42 \\
\hline Median & 40.00 & 50.00 & 52.50 & 45.00 & 55.00 & 60.00 & 45.00 & 55.00 & 50.00 & 50.00 & 55.00 & 55.00 \\
\hline MAD & 22.24 & 7.41 & 11.12 & 7.41 & 7.41 & 0.00 & 7.41 & 7.41 & 14.83 & 14.83 & 7.41 & 7.41 \\
\hline
\end{tabular}
ASQ-3 dimension 


\section{MlMacrothink}

Global Journal of Educational Studies

ISSN 2377-3936

2018, Vol. 4, No. 1

\begin{tabular}{lcccccccccccc}
\hline \multicolumn{2}{l}{ Problem solving } & & & & & & & & & & & \\
Mean & 30.00 & 46.25 & 51.88 & 36.11 & 50.93 & 54.44 & 40.02 & 52.90 & 50.99 & 42.03 & 52.74 & 51.99 \\
SD & 17.19 & 12.00 & 12.41 & 14.43 & 9.41 & 6.70 & 12.72 & 9.93 & 10.60 & 12.39 & 9.66 & 9.90 \\
Median & 30.00 & 45.00 & 60.00 & 40.00 & 50.00 & 55.00 & 40.00 & 60.00 & 55.00 & 45.00 & 60.00 & 55.00 \\
MAD & 18.53 & 14.83 & 0.00 & 14.83 & 7.41 & 7.41 & 14.83 & 0.00 & 7.41 & 7.41 & 0.00 & 7.41 \\
Personal-social & & & & & & & & & & & \\
Mean & 31.46 & 44.17 & 52.71 & 32.41 & 47.78 & 56.85 & 32.92 & 52.01 & 54.67 & 37.95 & 54.17 & 55.62 \\
SD & 15.21 & 14.57 & 9.67 & 17.12 & 10.13 & 4.83 & 12.78 & 9.19 & 7.92 & 10.98 & 7.47 & 7.50 \\
Median & 30.00 & 47.50 & 55.00 & 30.00 & 50.00 & 60.00 & 35.00 & 55.00 & 60.00 & 40.00 & 55.00 & 60.00 \\
MAD & 14.83 & 11.12 & 7.41 & 22.24 & 7.41 & 0.00 & 14.83 & 7.41 & 0.00 & 14.83 & 7.41 & 0.00 \\
\hline
\end{tabular}

To check for differences and interactions across age and sex, a robust Bayesian regression was performed. Instead of using a normal distribution for the error term, Student's $T$ distribution was used because of its fatter tails. This procedure allows outliers to have a smaller Mean Square Error in the likelihood and thus less influence on the regression results.

NUTS, a Markov chain Monte Carlo (MCMC) method, generated a large and representative sample from the posterior distribution, and the Highest Density Interval (HDI) was computed from these results. When the HDI does not include a null value, it is possible to conclude that the probability of observing such a value is less than 95\% (Kruschke, 2011). This procedure is somewhat analogous to the Null Hypothesis Significance Testing confidence interval, but it allows the assumption of a probability statement of the parameter given the data that are analyzed. See Table 3 for the results.

Table 3. Longitudinal growth curve (1-3 years and 2-4 years)

\begin{tabular}{|c|c|c|c|c|c|c|c|c|c|c|}
\hline \multicolumn{6}{|c|}{ 1-3 years } & \multicolumn{5}{|c|}{ 2-4 years } \\
\hline & $\beta$ & SE & 1-CI & $\mathrm{u}-\mathrm{CI}$ & $\begin{array}{c}\text { Eff. } \\
\text { Sample }\end{array}$ & $\beta$ & SE & 1-CI & $\mathrm{u}-\mathrm{CI}$ & $\begin{array}{c}\text { Eff. } \\
\text { Sample }\end{array}$ \\
\hline \multicolumn{11}{|c|}{ Communication } \\
\hline Intercept & 36.76 & 2.59 & 31.71 & 41.83 & 4311 & 42.14 & 0.66 & 40.86 & 43.46 & 5382 \\
\hline Female & 4.11 & 3.57 & -2.76 & 11.09 & 3988 & 3.65 & 1 & 1.72 & 5.62 & 4844 \\
\hline Age & 7.58 & 2.00 & 3.73 & 11.51 & 4096 & 6.36 & 0.51 & 5.36 & 7.35 & 4869 \\
\hline Female:Age & -0.17 & 2.74 & -5.62 & 5.13 & 3663 & -1.81 & 0.78 & -3.35 & -0.28 & 4241 \\
\hline \multicolumn{11}{|l|}{ Gross motor } \\
\hline Intercept & 45.43 & 1.89 & 41.75 & 49.13 & 4848 & 52.63 & 0.43 & 51.78 & 53.48 & 4498 \\
\hline Female & 2.4 & 2.59 & -2.74 & 7.36 & 4783 & -0.87 & 0.64 & -2.1 & 0.37 & 3786 \\
\hline Age & 7.29 & 1.46 & 4.46 & 10.12 & 4593 & 3.03 & 0.33 & 2.39 & 3.7 & 4199 \\
\hline Female:Age & -1.37 & 2.01 & -5.29 & 2.58 & 4329 & 0.24 & 0.5 & -0.71 & 1.2 & 3479 \\
\hline \multicolumn{11}{|l|}{ Fine motor } \\
\hline Intercept & 39.08 & 2.39 & 34.47 & 43.74 & 4394 & 44.94 & 0.69 & 43.6 & 46.28 & 4737 \\
\hline Female & 4.76 & 3.28 & -1.73 & 11.1 & 3809 & 0.67 & 1.04 & -1.38 & 2.72 & 3921 \\
\hline Age & 5.53 & 1.85 & 1.89 & 9.16 & 3923 & 1.81 & 0.53 & 0.79 & 2.87 & 4327 \\
\hline Female:Age & -0.1 & 2.55 & -4.98 & 4.97 & 3417 & 1.21 & 0.81 & -0.38 & 2.78 & 3625 \\
\hline \multicolumn{11}{|c|}{ Problem solving } \\
\hline Intercept & 31.83 & 2.33 & 27.19 & 36.41 & 4426 & 42.49 & 0.6 & 41.33 & 43.67 & 5061 \\
\hline Female & 6.19 & 3.25 & -0.16 & 12.52 & 3914 & 1.45 & 0.88 & -0.27 & 3.18 & 4465 \\
\hline Age & 10.93 & 1.81 & 7.44 & 14.52 & 4264 & 5.48 & 0.46 & 4.57 & 6.37 & 4832 \\
\hline Female:Age & -1.75 & 2.51 & -6.81 & 3.11 & 3654 & -0.5 & 0.69 & -1.88 & 0.85 & 4011 \\
\hline \multicolumn{11}{|c|}{ Personal-social } \\
\hline Intercept & 32.19 & 2.36 & 27.65 & 36.87 & 4381 & 35.66 & 0.55 & 34.61 & 36.73 & 4799 \\
\hline Female & 1.26 & 3.25 & -5.18 & 7.67 & 3844 & 4.74 & 0.82 & 3.16 & 6.32 & 3579 \\
\hline Age & 10.6 & 1.81 & 7.06 & 14.09 & 4008 & 10.87 & 0.43 & 10.04 & 11.72 & 3688 \\
\hline Female:Age & 1.63 & 2.5 & -3.28 & 6.57 & 3407 & -2.03 & 0.64 & -3.29 & -0.79 & 3091 \\
\hline
\end{tabular}




\section{Macrothink}

Global Journal of Educational Studies

ISSN 2377-3936 2018, Vol. 4, No. 1

Significant main effects of sex and age were found. Females had higher scores than males in the communication and personal-social domains. The main effect of age showed that ASQ scores became higher as the child got older. We emphasize that the ASQ was developed as a screening tool and not as a longitudinal measurement. However, higher scores indicate that additional developmental milestones are attained, but the sample of behavior is small (i.e., six items per domain). No interactions were found, suggesting the absence of moderation effects between the children's age and gender. Figure 1 shows the children's growth curves.

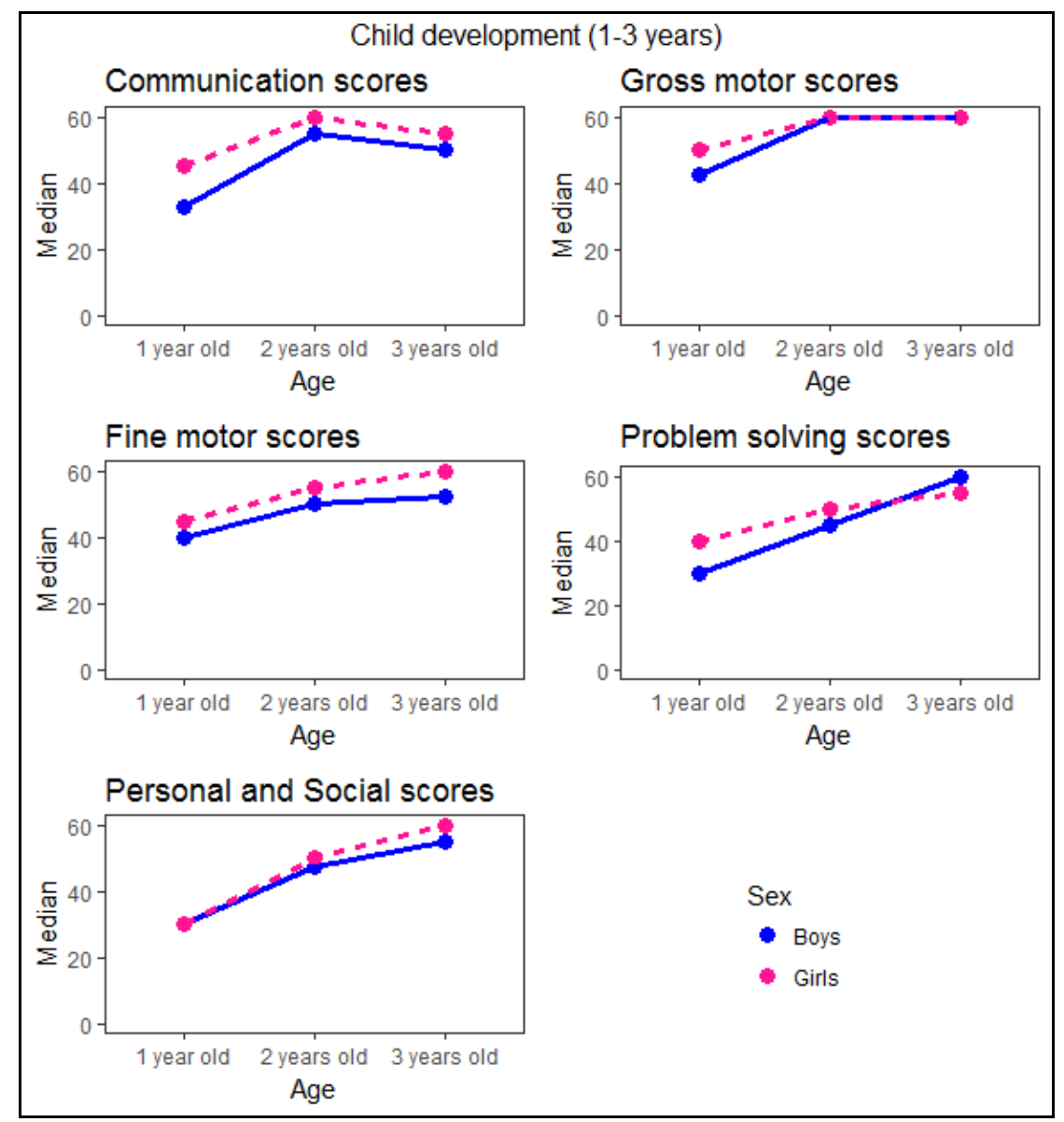




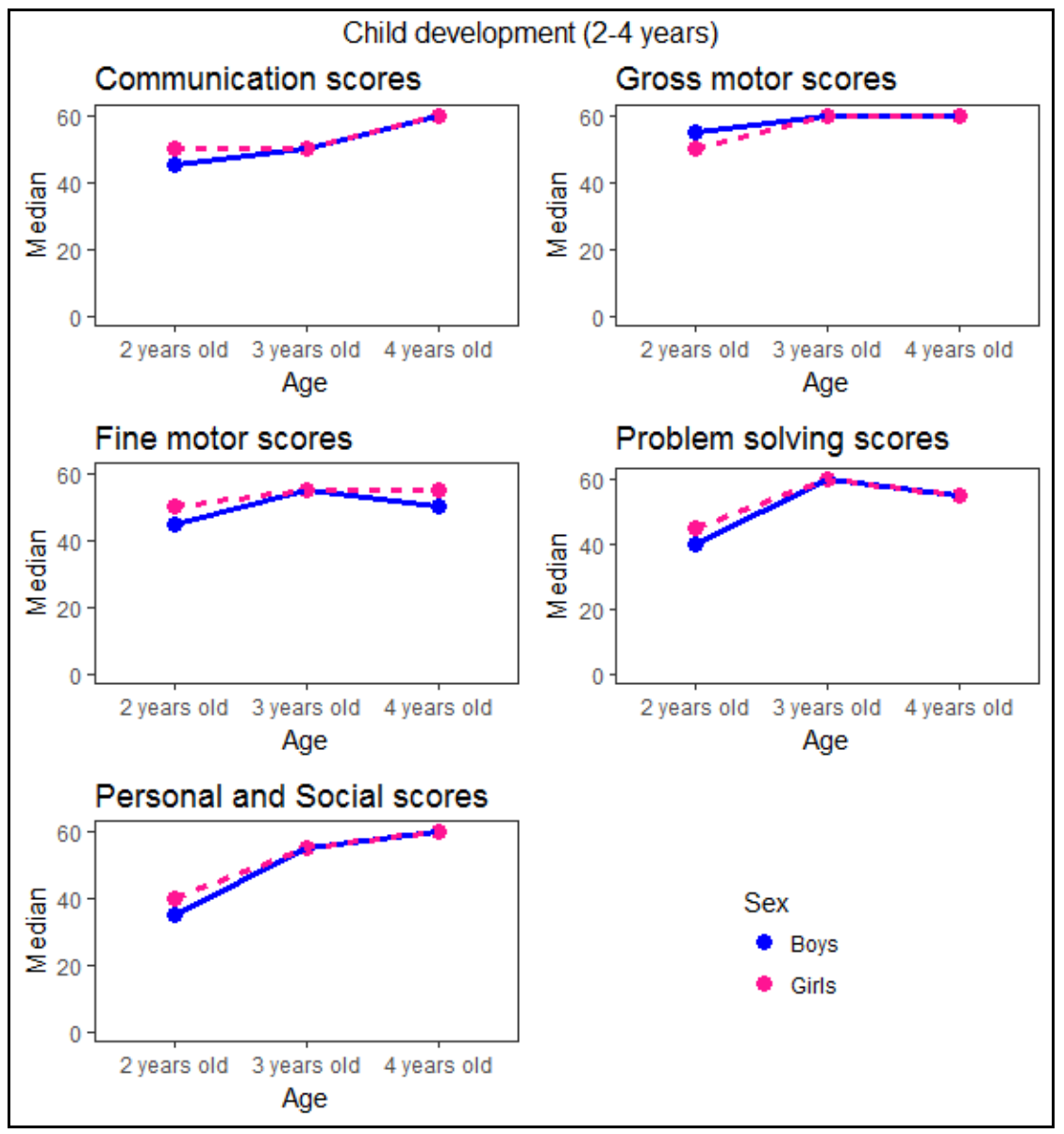

Figure 1. The children's growth curves

\section{Discussion}

The study of child development in low- and middle-income countries is an important issue in the political realm and has received substantial attention in Brazil (de Martino Jannuzzi, 2002). There are at least two reasons for this emphasis. First, strong causal evidence suggests that disrupted or delayed early development has long-term negative consequences for children, which is also true for children who are exposed to multiple risks (e.g., poverty and birth trauma; van Heerden et al., 2017; Wallander et al., 2014). Second, economic investment in children could yield high rates of return (up to nine times) in poor countries, assessed by such outcomes as income and employment rates (Campbell et al., 2014; Stenberg et al., 2014).

The present study investigated five domains of child development in children who were enrolled in public daycare centers in Brazil and explored the relationships between gender and age to better understand and explain the results. Our main findings suggest gender and age differences. Girls outperformed boys in communication and personal-social skills, and the children's scores improved as they got older. The absence of an interaction between age and gender indicates that the two main effects occurred independently of each other and can be treated separately (Gelman et al., 2004).

With regard to communication skills, similar results have been reported by others (Catino et al., 2017; Filgueiras et al., 2013). From birth to the first year of life, female infants present stronger social orientation responses than male infants, with more interest in human faces, a 
greater amount of eye contact, and more accurate imitative abilities. Females exhibit activation of the left prefrontal cortex more often than males, suggesting a greater degree of executive processing and language-based decoding, with greater activation of mesolimbic regions. These abilities remain stable until later in life and are especially related to peer interactions and different interaction and communication styles (Wang et al., 2012).

Personal-social skills contribute to young children's self-help and adaption skills and include different socially acceptable behaviors that enable children to enter interpersonal relationships and interact with others and their environment. Other studies have shown that girls are, on average, more socially competent than boys. One explanation for this might lie in the fact that boys are more physically active, engage in more risk-taking behavior and rough-and-tumble play, and exhibit more anger and aggression toward peers than girls. Girls engage in more dyadic play and prefer the company of their mostly female preschool teachers (Vahedi, Farrokhi, \& Farajian, 2012). Because the evaluation was performed by teachers, this process could have influenced the evaluation process. Numerous empirical studies have established that teachers perceive girls as more socially skilled than boys (O'Brennan, Bradshaw, \& Furlong, 2014), which could have influenced the teachers' ratings.

The present study has several limitations. One limitation is related to public daycare centers. Another limitation is related to data gathering. Frequently, children who are enrolled in Brazilian public daycare centers are in an economically disadvantaged situation, and this compromises further generalization for children with different demographic characteristics. We could not form a control group to measure the effect of the daycare facility itself on child development, which prevents us from claiming causal relationships between variables. We emphasize the both limitations are intrinsic to ethical standards and related to our research question.

One of the most important predictors of adult life satisfaction is emotional health in childhood. Monitoring this process enables the prevention and early detection of diseases and developmental disturbances in infancy and childhood (Campbell et al., 2014). Early identification and intervention lead to better social emotional and academic outcomes.

\section{Conclusion}

The present study investigated the development of children who were enrolled in public daycare centers in Brazil and assessed age and year differences and interactions based on ASQ-BR scores. The findings suggest that children who are enrolled in Brazilian public daycare centers, despite environmental adversity, are not at risk of serious developmental delays.

\section{References}

Armijo, I., Schonhaut, L., \& Cordero, M. (2015). Validation of the Chilean version of the Ages and Stages Questionnaire (ASQ-CL) in community health settings. Early Human Development, 91(12), 671-676. https://doi.org/10.1016/j.earlhumdev.2015.10.001

Bricker, D., Macy, M., Squires, J., \& Marks, M. (2013). Developmental screening in your community: an integrated approach for connecting children with services. Baltimore: Paul Brookes.

Bürkner, P. C. (2017). BRMs: An R package for Bayesian multilevel models using Stan. Journal of Statistical Software, 80(1). https://doi.org/10.18637/jss.v080.i01 
Campbell, F., Conti, G., Heckman, J. J., Moon, S. H., Pinto, R., Pungello, E., \& Pan, Y. (2014). Early childhood investments substantially boost adult health. Science, 343(6178), 1478-1485. https://doi.org/10.1126/science.1248429

Catino, E., Di Trani, M., Giovannone, F., Manti, F., Nunziata, L., Piccari, F., Sirchia, V., Vannucci, L., \& Sogos, C. (2017). Screening for developmental disorders in 3- and 4-year-old Italian children: A preliminary study. Frontiers in Pediatrics, 5, 181. https://doi.org/10.3389/fped.2017.00181

De Martino Jannuzzi, P. (2002). Indicadores Sociais na Formulação e Avaliação de Políticas Públicas. Retrieved from http://antigo.enap.gov.br/downloads/ec43ea4findic-curso-texto.pdf

Ding, P. (2014). Bayesian robust inference of sample selection using selection: $T$ models. Journal of Multivariate Analysis, 124, 451-464. https://doi.org/10.1016/j.jmva.2013.11.014

Elwick, A. (2018). New forms of government school provision: An international comparison. $\begin{array}{lllll}\text { Journal of } & \text { Education 206-225. }\end{array}$ https://doi.org/10.1080/02680939.2017.1329551

Ertem, I. O., Dogan, D. G., Gok, C. G., Kizilates, S. U., Caliskan, A., Atay, G., Vatandas, N., Karaaslan, T., Baskan, S. G., \& Cicchetti, D. V. (2008). A guide for monitoring child development in low- and middle-income countries. Pediatrics, 121(3), e581-e589. https://doi.org/10.1542/peds.2007-1771

Filgueiras, A., Pires, P., Maissonette, S., \& Landeira-Fernandez, J. (2013). Psychometric properties of the Brazilian-adapted version of the Ages and Stages Questionnaire in public child daycare centers. Early Human Development, 89(8), 561-576. https://doi.org/10.1016/j.earlhumdev.2013.02.005

Fonseca, F. F., Sena, R. K. R., dos Santos, R. L. A., Dias, O. V., \& de Melo Costa, S. (2013). As vulnerabilidades na infância e adolescência e as políticas públicas brasileiras de intervenção. Revista Paulista de Pediatria, 31(2), 258-264. https://doi.org/10.1590/S0103-05822013000200019

Gelman, A., Carlin, J. B., Stern, H. S., \& Rubin, D. B. (2004). Bayesian data analysis. Boca Raton: Chapman and Hall. https://doi.org/10.1007/s13398-014-0173-7.2

Heo, K. H., \& Squires, J. (2012). Cultural adaptation of a parent completed social emotional screening instrument for young children: Ages and Stages Questionnaire-Social Emotional. Early Human Development, 88(3), 151-158. https://doi.org/10.1016/j.earlhumdev.2011.07.019

Kruschke, J. K. (2011). Bayesian assessment of null values via parameter estimation and model comparison. Perspectives on Psychological Science, 6(3), 299-312. https://doi.org/10.1177/1745691611406925

Myung, I. J. (2003). Tutorial on maximum likelihood estimation. Journal of Mathematical Psychology, 47(1), 90-100. https://doi.org/10.1016/S0022-2496(02)00028-7

O’Brennan, L. M., Bradshaw, C. P., \& Furlong, M. J. (2014). Influence of classroom and school climate on teacher perceptions of student problem behavior. School Mental Health, 6(2), 125-136. https://doi.org/10.1007/s12310-014-9118-8

R Development Core Team. (2016). R: A language and environment for statistical computing. Vienna: R Foundation for Statistical Computing. https://doi.org/10.1038/sj.hdy.6800737 


\section{Al Macrothink}

Global Journal of Educational Studies

ISSN 2377-3936

2018, Vol. 4, No. 1

Rio de Janeiro City. (2017). Quick guide to public policies. Rio de Janeiro. Retrieved from http://www.rio.rj.gov.br/dlstatic/10112/4379008/4130265/EducacaoING1211.pdf

Rouder, J. N., Morey, R. D., Speckman, P. L., \& Province, J. M. (2012). Default Bayes factors for ANOVA designs. Journal of Mathematical Psychology, 56(5), 356-374. https://doi.org/10.1016/j.jmp.2012.08.001

Schonhaut, L., Armijo, I., Schonstedt, M., Alvarez, J., \& Cordero, M. (2013). Validity of the Ages and Stages Questionnaires in term and preterm infants. Pediatrics, 131(5), e1468-e1474. https://doi.org/10.1542/peds.2012-3313

Stenberg, K., Axelson, H., Sheehan, P., ... \& Bustreo, F. (2014). Advancing social and economic development by investing in women's and children's health: A new Global Investment Framework. Lancet, 383(9925), 1333-1354. https://doi.org/10.1016/S0140-6736(13)62231-X

Vahedi, S., Farrokhi, F., \& Farajian, F. (2012). Social competence and behavior problems in preschool children. Iranian Journal of Psychiatry, 7(3), 126-134.

Van Heerden, A., Sen, D., Desmond, C., Louw, J., \& Richter, L. (2017). App-supported promotion of child growth and development by community health workers in Kenya: Feasibility and acceptability study. JMIR mHealth and uHealth, 5(12), e182. https://doi.org/10.2196/mhealth.6911

Wallander, J. L., Bann, C. M., Biasini, F. J., ... , \& Carlo, W. A. (2014). Development of children at risk for adverse outcomes participating in early intervention in developing countries: A randomized controlled trial. Journal of Child Psychology and Psychiatry, 55(11), 1251-1259. https://doi.org/10.1111/jcpp.12247

Wang, Y., Adamson, C., Yuan, W., Altaye, M., Rajagopal, A., Byars, A. W., \& Holland, S. K. (2012). Sex differences in white matter development during adolescence: A DTI study. Brain Research, 1478, 1-15. https://doi.org/10.1016/j.brainres.2012.08.038

Wei, M., Bian, X., Squires, J., Yao, G., ... , \& Chen, J. (2015). [Studies of the norm and psychometrical properties of the Ages and Stages Questionnaires, third edition, with a Chinese national sample]. Chinese Journal of Pediatrics, 53(12), 913-918. Retrieved from http://www.ncbi.nlm.nih.gov/pubmed/26887546

\section{Copyright Disclaimer}

Copyright for this article is retained by the author(s), with first publication rights granted to the journal.

This is an open-access article distributed under the terms and conditions of the Creative Commons Attribution license (http://creativecommons.org/licenses/by/3.0/). 